Document downloaded from:

http://hdl.handle.net/10251/149534

This paper must be cited as:

Tanov, S.; Salvador-lborra, J.; Andersson, Ö.; Olmeda, P.; García Martínez, A. (2017). Influence of the number of injections on piston heat rejection under low temperature combustion conditions in an optical compression-ignition engine. Energy Conversion and Management. 153:335-345. https://doi.org/10.1016/j.enconman.2017.10.015

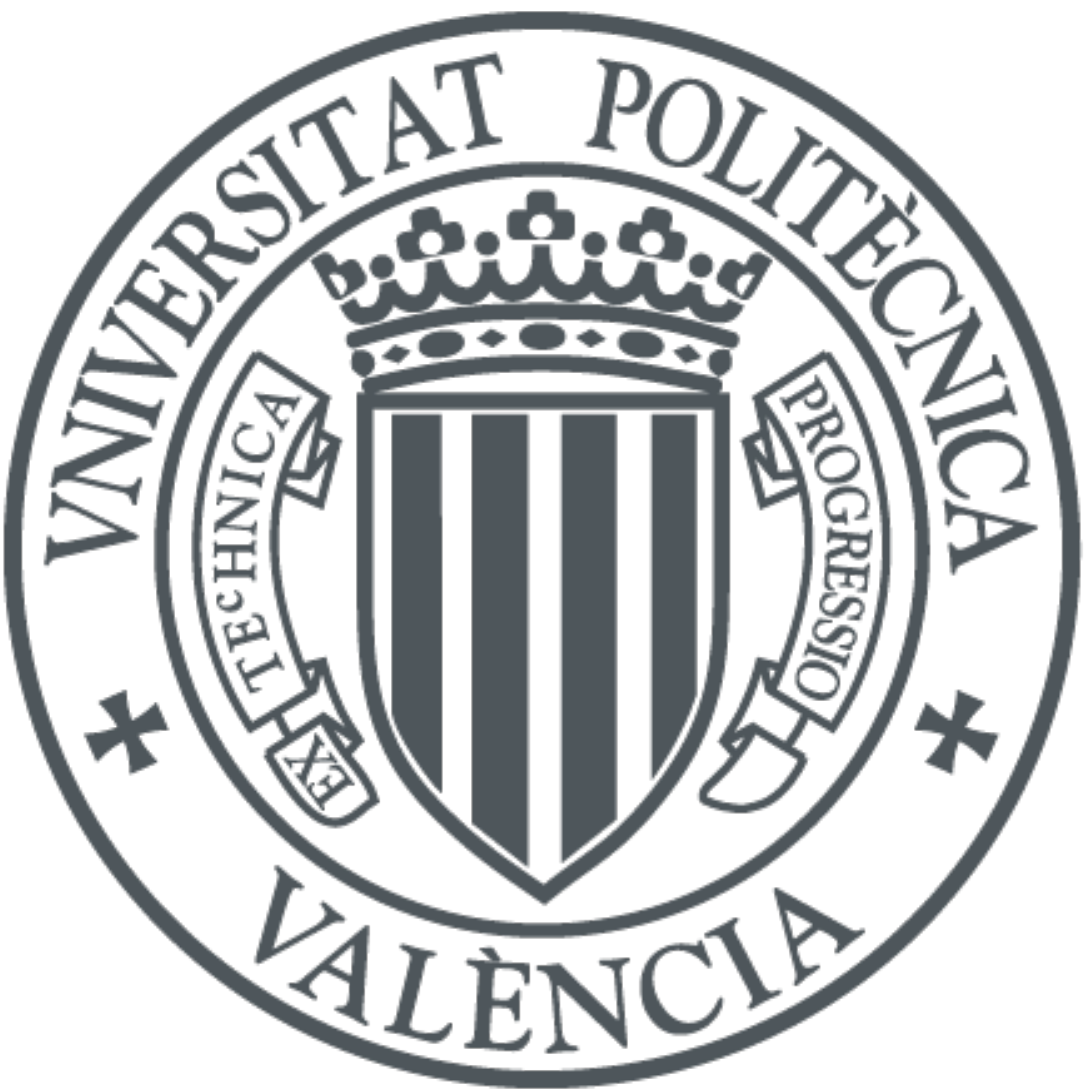

The final publication is available at

https://doi.org/10.1016/j.enconman.2017.10.015

Copyright Elsevier

Additional Information 


\title{
Influence of the number of injections on piston heat rejection under Low Temperature Combustion conditions in an optical compression-ignition engine
}

\author{
Slavey Tanov ${ }^{a}$, Josep Salvador-Iborra ${ }^{b}$, Öivind Andersson ${ }^{a}$, \\ Pablo Olmeda* ${ }^{* b}$, Antonio García ${ }^{b}$
}

${ }^{a}$ Div. Combustion Engines, Dept. Energy Sciences, Lund University, 22362 Lund, Sweden

${ }^{b}$ CMT-Motores Térmicos, Universitat Politècnica de València, Camí de Vera s/n, 46022 Valencia, Spain

\begin{abstract}
New combustion concepts are being investigated to develop cleaner engines. One of the most promising is partially premixed combustion. The mechanisms of this combustion mode and its impact on performance and emissions have been studied in the previous years. Nevertheless, little research has been done from the point of view of heat transfer. In particular, the influence of the injection strategy on heat transfer is of great interest in partially premixed combustion. This work presents a method to calculate convective heat transfer to the piston. The method uses a combination of gas velocity models and experimental velocity data measured with the PIV technique. This method was applied to achieve the goal of studying the effect of the number of injections on heat rejection. First, the influence of the injection strategy on gas motion was examined. To do that, an analysis of the velocity components relevant to gas-surface convection was conducted, as well as of the resulting heat transfer coefficient. Next, heat flux results were discussed. The single injection strategy showed the highest heat transfer, followed by triple injection and double injection. Important instantaneous variations of heat flux were observed at different locations of the piston bowl. All findings were associated with concurring conditions of high gas velocity, density and temperature.
\end{abstract}

Keywords: PIV, heat transfer, heat transfer coefficient, PPC

* Corresponding author. Tel.: +34 963877650.

E-mail address: pabolgon@mot.upv.es (P. Olmeda). 


\section{Introduction}

Research in the automotive industry is exploring new technologies to comply with emissions regulations [1][2]. Low temperature combustion [3] is a promising concept to reduce emissions of internal combustion engines while keeping a high indicated efficiency [4]. Among the technologies achieving this low temperature combustion, gasoline partially premixed combustion (PPC) is one of the most interesting [5]. PPC in compression-ignition engines has shown potential of limiting the crucial soot and $\mathrm{NO}_{x}$ emissions in comparison with conventional diesel combustion [6]. PPC occurs when an early injection allows time for a better fuel-air mixture [7]. After ignition, a long, premixed, low-temperature combustion takes place. EGR and fuels with greater resistance to ignition [8] contribute to increase the ignition delay and thus extend the mixing time [9]. A drawback of PPC is combustion noise, which is higher than in conventional diesel combustion due to the higher pressure-rise rate [10]. Reported strategies to mitigate noise in PPC are multiple injection [11], EGR and optimization of the injection profile [12]. In-cylinder fuel stratification is key in PPC [13]. Thus, injection timing [14] and number of injections become decisive parameters. Several studies of PPC have analyzed the influence of the number of injections on several aspects of engine performance [15] but not on heat rejection. Nonetheless, heat transfer is a significant process in internal combustion engines that affects many aspects of its performance. It is an important factor for thermal efficiency, volumetric efficiency, emissions formation, lubrication and cooling [16]. A relevant study was carried out by Cho et al. [17]. They measured instantaneous heat fluxes under conditions of stratified combustion. Heat transfer was reduced up to $30 \%$ in comparison with homogeneous operation. A research about heat rejection under PPC operation was conducted by Fridriksson et al. [18]. The CFD study assessed the potential of combining PPC and thermal insulation. They found that the consequent increase of $\mathrm{NO}_{x}$ emissions was effectively limited with PPC in comparison with the conventional diesel combustion case.

Convective heat transfer depends on in-cylinder gas motion, hence the need to understand the flow structures in the combustion chamber in order to investigate heat losses. Morel [19] wrote a comprehensive report about the relation between gas motion and heat rejection which became a sound reference for researchers. In-cylinder swirl motion has received special attention from researchers because of its clear influence on increasing heat transfer [20]. The in-cylinder flow structure is also critical for PPC because of its influence on the fuel-air mixing process [21]. These patterns of incylinder gas movement can be studied by means of optically accessible engines [22][23]. An outstanding technique to conduct this kind of research is particle image velocimetry (PIV) [24]. Many authors have applied PIV and other optical techniques to engine research [25][26][27], but few studies have related measurements in optical engines to heat transfer. Lucht et al. [28] used the coherent anti-Stokes Raman scattering (CARS) technique to measure the gas temperatures near the cylinder head surface and also measured heat flux. Steeper and Stevens measured temperatures in an optical

Abbreviations: CAD, crank angle degree; D, diameter; EGR, exhaust gas recirculation; HTC, heat transfer coefficient; $\mathrm{HRR}$, heat release rate; $\mathrm{NO}_{x}$, nitrogen oxides; $\mathrm{O}_{2}$, oxygen; PIV, particle image velocimetry; PPC, partially premixed combustion; $\dot{q}$, heat flux density; $\mathrm{T}$, temperature; TDC, top dead center; TKE, turbulent kinetic energy; v, velocity. 
piston. After comparing with an aluminum piston, they concluded that temperatures of the fused-silica piston were significantly greater [29]. Ma et al. [30] used high-speed $\mu$-PIV measurements of the boundary layer to develop a wall-function model with a consistent heat transfer model. They suggested that a non-equilibrium wall-function model could provide better accuracy for predicting convective heat transfer than an equilibrium wall-function model. Garcia-Oliver et al. [31] investigated the swirl-spray interaction with PIV on a horizontal plane. They observed a reduction of swirl velocity and turbulence when energizing time increased. Higher injection pressures also led to decrease swirl ratio. Both effects were associated with a lowered convective heat transfer coefficient.

The aim of the present study is to compare heat rejection to various areas of the engine piston with different injection strategies. To achieve that, a method is presented to determine heat transfer from gas velocity. The velocity data came from PIV measurements and computational models and it was used to calculate the heat transfer coefficient between the gas and the cylinder walls. Velocity measurements were treated and processed to obtain two outcomes: the velocity components tangential to the piston surfaces and the turbulent kinetic energy. Swirl motion and piston wall temperatures were estimated by means of computational models. Discussion starts dealing with the effect of the number of injections on the mentioned velocity components and on the final characteristic velocity in different areas of the piston bowl. Then, the resulting heat transfer coefficients are examined. Next analysis focuses on the instantaneous evolution of heat flux and its variation with different number of injections at different locations. Finally, the influence of the injection strategy on the global heat transfer rate is explained.

\section{Experimental and theoretical tools}

Various sources were used to gather the necessary data. In this section, the experiment that yielded the PIV measurements is reported. Next, the computational models used to obtain swirl velocities and wall temperatures are described.

\subsection{Experimental data}

PIV data was obtained from an experiment conducted by Tanov et al. at the Combustion Engine Department of Lund University. The experiment is described in detail in reference [32]. Engine tests were made under PPC conditions in an optical engine with a realistic piston bowl. The engine will be named Engine 1 in this paper. Engine characteristics are summarized in table 1. HSPIV (high-speed particle image velocimetry) technique was applied on a vertical plane. Image pairs acquired with a high speed camera were dewarped and processed to obtain the velocity vectors. Measurements were made with one, two and three injections at the time span between 20 CAD before TDC and 20 CAD after TDC. The tests were conducted at the same mean effective pressure. 44 repetitions of each experiment were recorded. In-cylinder pressure was measured with a piezoelectric transducer. This pressure signal allowed to obtain the HRR through the first law analysis [33] and the gas temperature with the ideal gas equation. According to Lapuerta et al., employing the ideal gas equation in combustion flow instead of a more complex correlation yields small and localized overestimations up to $2.1 \%$ [34]. To obtain gas temperature, influential phenomena such 
as fuel evaporation and mass leakage were taken into account [35]. Table 2 contains the instrumentation data.

Table 1: Specifications of engine 1.

\begin{tabular}{lc}
\hline Bore, mm & 81 \\
Stroke, mm & 92.3 \\
Bowl diameter, mm & 48.2 \\
Bowl depth, mm & 14.8 \\
Squish height, mm & 4.9 \\
Compression ratio & $11.3: 1$ \\
\hline
\end{tabular}

Table 2: Instrumentation.

\begin{tabular}{llc}
\hline Variable & Instrument & Accuracy \\
\hline Crank angle, engine speed & Encoder & $\pm 0.02 \mathrm{CAD}$ \\
In-cylinder pressure & Piezoelectric transducer & $\pm 1.25 \mathrm{bar}$ \\
Intake pressure & Piezorresistive transducer & $\pm 25 \mathrm{mbar}$ \\
Intake and coolant temperatures & k-type thermocouple & $\pm 2^{\circ} \mathrm{C}$ \\
$\mathrm{O}_{2}$ concentration & Gas analyzer & $4 \%$ \\
\hline
\end{tabular}

\subsection{Swirl model}

Due to the experiment configuration, PIV measurements were circumscribed within a vertical plane inside the piston bowl. The plane provided information regarding the gas movement in axial and radial directions, but not around the cylinder axis, which is called swirl motion. Swirling velocity of the gas was needed to calculate the heat transfer coefficient because swirl is tangential to all surfaces of the cylinder. Hence, a 1-D model was used to obtain the swirl velocity. The model is similar to the one proposed by Murakami [36], which was formed by two rotating rigid-body gas volumes. The variation of angular momentum in each volume is described by an expression of the kind of equation 1 .

$$
\frac{d\left(I_{i} \omega_{i}\right)}{d t}=\tau_{i, s q u i s h}+\tau_{i, v i s c}+\sum_{j} \tau_{f r i c, j}
$$

$I$ is the moment of inertia of the volume, $\omega$ is the angular velocity of the gas, $\tau_{\text {squish }}$ is the angular momentum flux transported between contacting volumes by the squish flow, $\tau_{v i s c}$ is the angular momentum flux transmitted between volumes by viscous shear and $\tau_{\text {fric }}$ is the friction moment between the gas and the wall. Subindex $i$ refers to the gas volume and $j$ to the different chamber surfaces. The two regions of the cylinder are an outer annular volume in contact with the liner and an inner cylindrical volume with the same diameter as the piston bowl. All results used in this paper are from the inner volume. Angular swirl velocity is considered uniform in the whole gas volume (rigid-body motion). 
A validation of the swirl model is provided next. Two engines were used for validation, named Engine 2 and Engine 3. Their specifications are given in table 3. Cross sections of the pistons can be seen in figure 1. Both are 4-stroke, compression ignition, direct injection diesel engines. Engine 2 is an all-metal production engine, while Engine 3 is an optical engine. First validation involves Engine 2. Simulations of in-cylinder gas motion were conducted with the commercial CFD code CONVERGE. A base mesh size of $2 \mathrm{~mm}$ was set. The code refined the mesh automatically to increase resolution in areas with high gradients of velocity and temperature. Thus, number of cells varied between 20000 and 200000. The computational domain included the combustion chamber with the real piston geometry. The simulated period was the whole closed cycle i.e. the extent of time between intake valves closing and exhaust valves opening. Simulation results were post-processed with Matlab to separate the data of the two cylinder regions that were described above. This allowed to compare swirl velocity in the inner region. The plot on the left side of figure 2 demonstrates that the model was able to predict swirl velocity in the piston bowl.

Table 3: Specifications of engines used for swirl model validation.

\begin{tabular}{lcc}
\hline Parameter & Engine 2 & Engine 3 \\
\hline Bore, mm & 82 & 85 \\
Stroke, mm & 90.4 & 96 \\
Bowl diameter, mm & 45.8 & 45 \\
Bowl depth, mm & 15.2 & 12 \\
Squish height, mm & 1.5 & 1.5 \\
Compression ratio & $17.5: 1$ & $15.2: 1$ \\
\hline
\end{tabular}
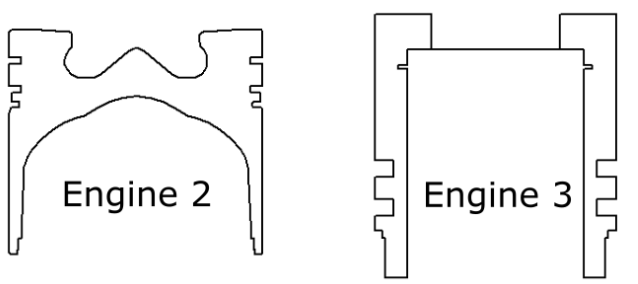

Figure 1: Pistons of Engine 2 and Engine 3.

To perform the validation with Engine 3, two submodels were added into the swirl model. The first one was a simple model of mechanical deformations of the piston and the connecting rod under the effects of pressure and inertia. The second one was an isentropic nozzle submodel for calculating blow-by. Both submodels are described in reference [37]. In order to apply the submodels to the study of a new engine, the calibration constants were adjusted with preliminary tests. Relevant geometrical parameters of the new engine were obtained to solve the expressions. Other submodel inputs were test variables such as gas pressure and temperature or engine speed. To study optical engines, it was particularly important to take into account blow-by because they presented very high blow-by rates. In Engine 1, blow-by was up to $35 \%$ 


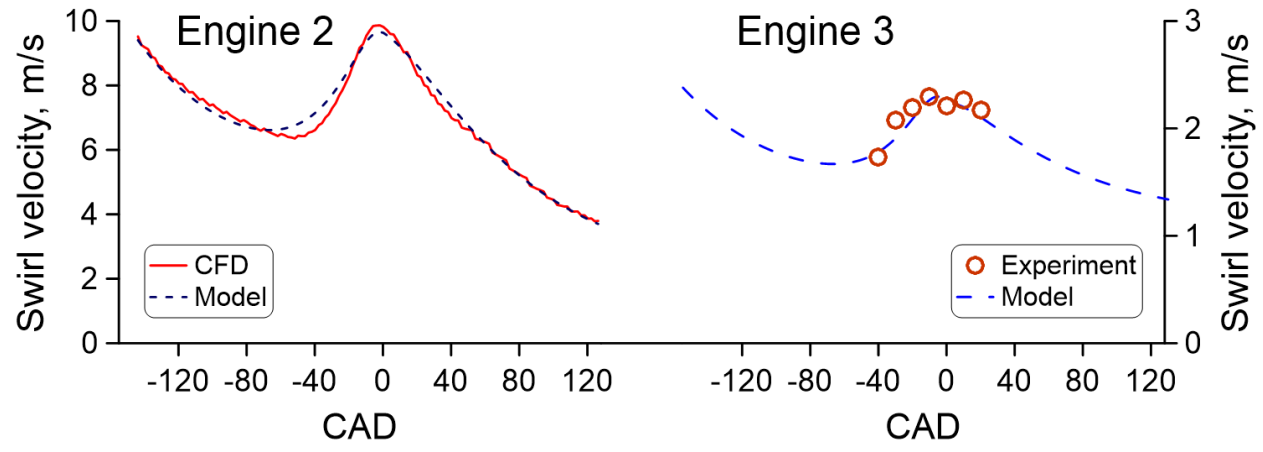

Figure 2: Swirl model predictions in other engines

while in Engine 3, it was up to $20 \%$. Blow-by rates were not measured directly; instead, they were obtained through simulations. Regarding mechanical deformations, Engine 1 had deformations up to $0.1 \mathrm{~mm}$ and in Engine 3 they were up to $1.5 \mathrm{~mm}$.

PIV technique was used in Engine 3 to proceed with the validation of the swirl model. A horizontal sheet allowed to observe the swirl movement in the bowl. On the right side of figure 2, experiment and model are compared. The modeled curve of swirl velocity presented good agreement with the experimental one.

\subsection{Wall temperature model}

An estimation of the piston temperature was needed to calculate heat transfer between the gas and the wall. For that, a lumped heat transfer model consisting of a thermal resistor/capacitor network was used. The thermal network is made up of nodes, each of which has a certain temperature. Heat flows from one node to another depending on the relative thermal resistance among them. A more detailed description of the model can be found in reference [38]. A representation of the nodal network can be seen in figure 3. A recent research [39] showed that the model was able to reproduce the influence of engine speed and swirl -which are parameters affecting gas velocity and convective heat transfer- and predict wall temperatures. In the present study, the lumped heat transfer model provided the mean surface temperature of the piston for the different tests. Those were necessary to calculate heat transfer as explained in section 3.4. Thermodynamic data from each experimental test was employed as boundary condition. Also, geometry and characteristics of the engine under study were used. Further details can be found in section 3.4. During a cycle of an internal combustion engine, wall temperatures swing very slightly in comparison with gas temperature (about $10 \mathrm{~K}$ in the solid versus $1000 \mathrm{~K}$ in the gas) [40][41]. Several factors contribute to this: the high heat capacity of the metallic structure, the relatively high thermal resistance between gas and wall and the short duration of a cycle [42]. 


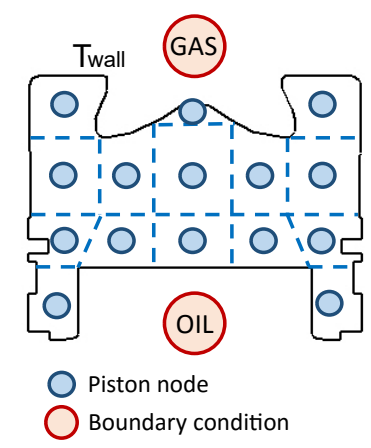

Figure 3: Lumped heat transfer model of piston

\section{Methods}

\subsection{Test matrix}

The test campaign consisted on three cases corresponding with three injection strategies: single double and triple injection. As reported in section 2.1, the target was to achieve the same indicated mean effective pressure (IMEP) for all tests. Due to differences in stratification, IMEP could be higher or lower than the desired value. This could be corrected by tuning the injection settings. In each test, the adjustment of injection timing and duration allowed to reach the target IMEP. Injection pressure, on the contrary, was kept constant. On the left side of table 4, the information about start of injection (SOI) and injection duration of each strategy can be found. SOI is given in degrees before TDC and duration in crank angle degrees. Other test conditions are given on the right side of table 4 .

Table 4: Test conditions.

\begin{tabular}{lcc}
\hline Case & SOI & Duration \\
\hline Single & 15 & 2.9 \\
Double & $60 / 16.5$ & $2.9 / 1.9$ \\
Triple & $62.5 / 29.5 / 17$ & $2.3 / 1.7 / 1.7$ \\
\hline \hline Variable & Value \\
\hline Engine speed & $800 \mathrm{rpm}$ \\
IMEP & $4 \mathrm{bar}$ \\
Injection pressure & $600 \mathrm{bar}$ \\
Intake pressure & $1.14 \mathrm{bar}$ \\
Intake temperature & $73^{\circ} \mathrm{C}$ \\
Intake $\mathrm{O}_{2}$ concentration & $17 \% \mathrm{vol}$ \\
Swirl ratio & 2.6 \\
Coolant temperature & $65{ }^{\circ} \mathrm{C}$ \\
\hline
\end{tabular}




\subsection{Tangential velocity on the PIV plane}

The experiment permitted to measure the velocity field in most of the piston bowl. Figure 4 displays the velocity field of the single injection case at different instants. It can be seen that gas velocity is far from homogeneous in the event of fuel injection. At a given instant, gas speed in the vicinity of the different surfaces can vary up to $20 \mathrm{~m} / \mathrm{s}$. The same is true for the evolution through time. Figure 5 shows the velocity field of the different injection strategies at the same instant. It confirms that the lack of homogeneity happens in the three tests.

The effective velocity for convective heat transfer is the velocity component tangential to the solid surface. However, the piston bowl has a complicated shape. To reproduce the convective heat transfer process accurately in these conditions, the bowl surface is divided into four smaller surfaces, as shown in figure 6. Each of the surfaces has a gas zone associated. The gas zones have a thickness equal to $10 \%$ the bowl diameter. This value is high enough to be larger than the boundary layer thickness [19] but low enough to avoid including areas far from the surface where velocity evolves distinctly. Circumferential symmetry was assumed for the surfaces and the gas volumes.
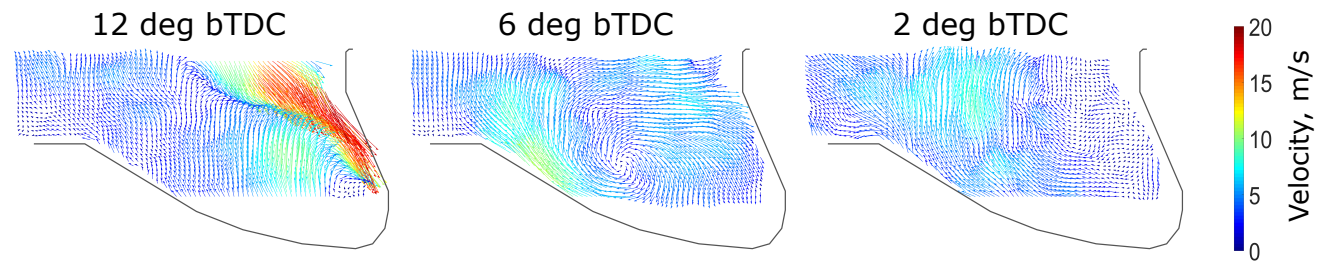

Figure 4: Velocity field at different instants
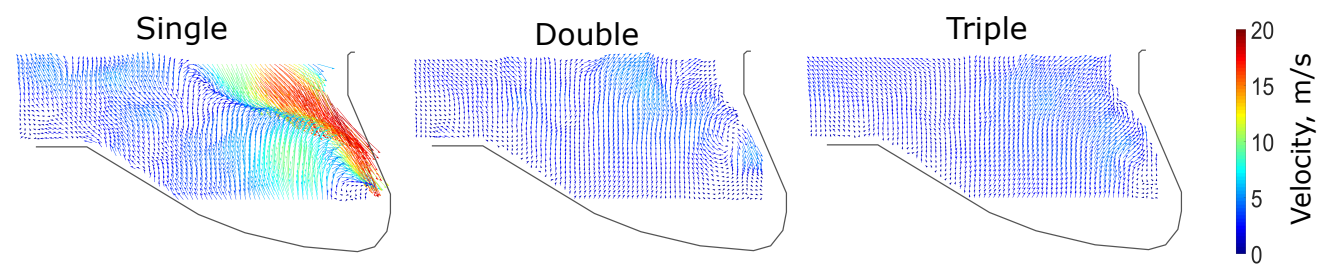

Figure 5: Velocity field with different injection strategies

In each zone, a unique mean velocity was obtained. The module and direction of the measured velocity vectors were averaged by means of equations 2 and $3 . i$ is every datapoint (measurement location) inside the zone and $N$ is the number of datapoints in the zone. $\theta$ is the current angle and $k$ is the current repetition. $v_{x}$ is the radial component of velocity of a datapoint at a certain instant and $v_{y}$ is the vertical component.

$$
\|v\|(\theta, k)=\frac{1}{N} \sum_{i=1}^{N} \sqrt{v_{x, i}^{2}(\theta, k)+v_{y, i}^{2}(\theta, k)}
$$




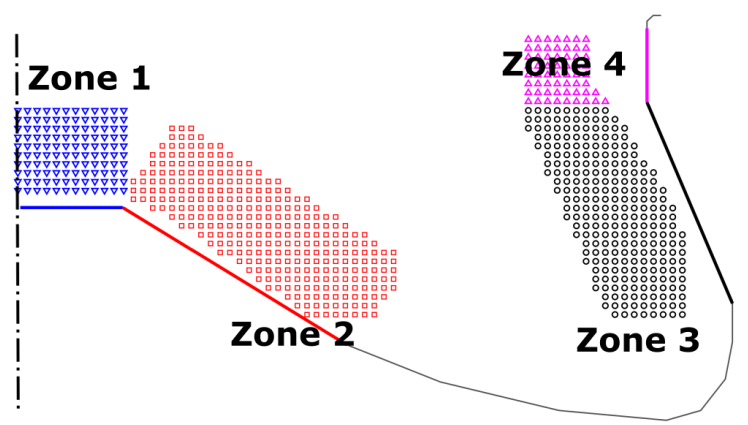

Figure 6: Zoning

$$
\Theta_{v}(\theta, k)=\frac{1}{N} \sum_{i=1}^{N} \operatorname{atan}\left(\frac{v_{y, i}(\theta, k)}{v_{x, i}(\theta, k)}\right)
$$

Results were then averaged for all repetitions to obtain $\|v\|(\theta)$ and $\Theta_{v}(\theta)$.

As previously noted, the effective velocity for convective heat transfer is tangential to the surface. The next step was to project the velocity vector defined by $\|v\|(\theta)$ and $\Theta_{v}(\theta)$ with equation 4. $\phi$ is the inclination angle of the surface in the same coordinate system as $\Theta_{v}$. A vector of $v_{\text {tangential }}(\theta)$ was obtained for each zone. This velocity was one of the components used during the study of gas-wall heat rejection.

$$
v_{\text {tangential }}(\theta)=\|v\|(\theta) \cos \left(\Theta_{v}(\theta)-\phi\right)
$$

\subsection{Turbulent kinetic energy}

Turbulent kinetic energy (TKE) is a remarkable contributor to in-cylinder gas motion [43]. In this work, TKE was obtained from the PIV measurements using a procedure based on the one described in reference [32]. TKE is computed in each zone with equation 5, where $v_{x}^{\prime}$ and $v_{y}^{\prime}$ are the instantaneous fluctuations of velocity. Again, $i$ is the datapoint and $N$ is the number of datapoints in each zone.

$$
\operatorname{TKE}(\theta)=\frac{1}{N} \sum_{i=1}^{N} \frac{{\overline{v_{x}^{\prime}}}^{2}(\theta, i)+{\overline{v_{y}^{\prime}}}^{2}(\theta, i)}{2}
$$

Equation 6 indicates how $v_{x}^{\prime}$ is calculated. The expression for $v_{y}^{\prime}$ is analogous. They are calculated as the standard deviation of velocity in each measurement location within a temporal window $M$. In this case, $M$ is 5 angle instants. The temporalwindow approach removes the influence of cycle-to-cycle dispersion [32]. $j$ is a counter of the instants, while $\overline{v_{x}}$ is the cycle-resolved average of $v_{x}$ at a certain location within the temporal window and it is obtained with equation $7 . \overline{v_{x}^{\prime}}$, needed in equation 5 , is the average of $v_{x}^{\prime}$ over all repetitions.

$$
v_{x}^{\prime}(\theta, i, k)=\sqrt{\frac{1}{M} \sum_{j=1}^{M}\left[v_{x}(\theta+2 j-M-1, i, k)-\overline{v_{x}}(\theta, i, k)\right]^{2}}
$$




$$
\overline{v_{x}}(\theta, i, k)=\frac{1}{M} \sum_{j=1}^{M} C(j) v_{x}(\theta+2 j-M-1, i, k)
$$

Finally, $C(j)$ is a weight factor given by equation 8 , where $\sum_{j=1}^{M} C(j)=1$, holds.

$$
C(j)=\frac{\sin \left(\pi \frac{j}{M+1}\right)}{\sum_{j=1}^{M} \sin \left(\pi \frac{j}{M+1}\right)}
$$

\subsection{Heat transfer calculation}

The fundamental outcome of this method is convective heat flux. In this study, the variable used in the comparison among injection strategies was heat flux density. This magnitude was calculated with Newton's law of cooling, expression 9. It represents the heat flux per unit area, allowing to compare heat rejection to surfaces with different areas.

$$
\dot{q}(\theta)=h(\theta)\left(T_{\text {gas }}(\theta)-T_{\text {wall }}\right)
$$

where $h$ is heat transfer coefficient between the gas and the cylinder wall and $T_{\text {gas }}$ is instantaneous gas temperature. Mean piston wall temperature $T_{\text {wall }}$ was estimated using the model described in section 2.3. Conductivity of the quartz piston was set to $1.3 \mathrm{~W} / \mathrm{mK}[44]$. The resulting temperatures are summarized in table 5 .

Table 5: Surface temperature of the piston

\begin{tabular}{cc}
\hline Test & Temperature, ${ }^{\circ} \mathrm{C}$ \\
\hline Single & 335.1 \\
Double & 328.6 \\
Triple & 325.6 \\
\hline
\end{tabular}

Gas-wall heat transfer coefficient $h$ was calculated with correlation 10 , due to Colburn [45] and used by Morel [19].

$$
h_{\text {Colburn }}=\frac{0.0565}{2} \rho(\theta) C_{p}(\theta) v_{\text {char }}(\theta)\left(\frac{\rho(\theta) L_{\text {char }}(\theta) v_{\text {char }}(\theta)}{\mu(\theta)}\right)^{-1 / 4} \operatorname{Pr}^{-2 / 3}(\theta)
$$

$\rho, C_{p}, \mu$ and $\operatorname{Pr}$ are density, specific heat, viscosity and Prandtl number of the gas, respectively. Along with the previous correlation, Morel proposed the following expression for the characteristic velocity:

$$
v_{\text {char }}(\theta)=\sqrt{v_{\text {tangential }}^{2}(\theta)+v_{\text {swirl }}^{2}(\theta)+2 T K E(\theta)}
$$

This formulation was considered appropriate by Morel because it took into account all key fluid motions responsible for convective heat transfer and was applicable to different subzones of the cylinder surface, thus providing a better spatial resolution. Morel modeled all relevant velocities but, in the present work, the experimental procedure allowed to calculate $v_{\text {tangential }}$ and TKE from measurements. $v_{\text {swirl }}$ was modeled 
with the same method used by Morel, as explained in section 2.2. Fluid properties were evaluated at film temperature, the mean between bulk gas temperature and wall temperature.

Finally, Morel also proposed approximations for the boundary layer thickness at the different surfaces and used this magnitude as characteristic length $L_{c h a r}$. He employed equation 12 at the lateral wall of the piston bowl and equation 13 at the bowl ground. In this work, equation 13 was applied to zones 1 and 2 and equation 12 to zones 3 and 4 (see figure 6 ). $H_{\text {bowl }}$ is the bowl depth, $s$ is the instantaneous distance between the piston top and the firedeck and $D_{\text {rim }}$ is the bowl diameter at the bowl rim. The values of $L_{\text {char }}$ for the present engine are plotted on the left side of figure 7. As a result of the previous definitions, the boundary layer thickness at the bowl ground evolves as a concave parabola while at the lateral wall it is constant. From equation 10, it is deduced that the parameter affecting HTC is $L_{c h a r}^{-0.25}$. If no

other variable of equation 10 changes, HTC will be proportional to $L_{\text {char }}^{-0.25}$. On the right side of figure 7, the sensitivity of HTC to the characteristic length is assessed. It can be seen that HTC at the bowl ground is between $29 \%$ and $33 \%$ higher than at the lateral wall.

$$
\begin{gathered}
L_{\text {char }}=0.05 D_{\text {bowl }} \\
L_{\text {char }}(\theta)=0.05\left(H_{\text {bowl }}+s(\theta)\left(\frac{D_{\text {rim }}}{D_{\text {bowl }}}\right)^{2}\right)
\end{gathered}
$$
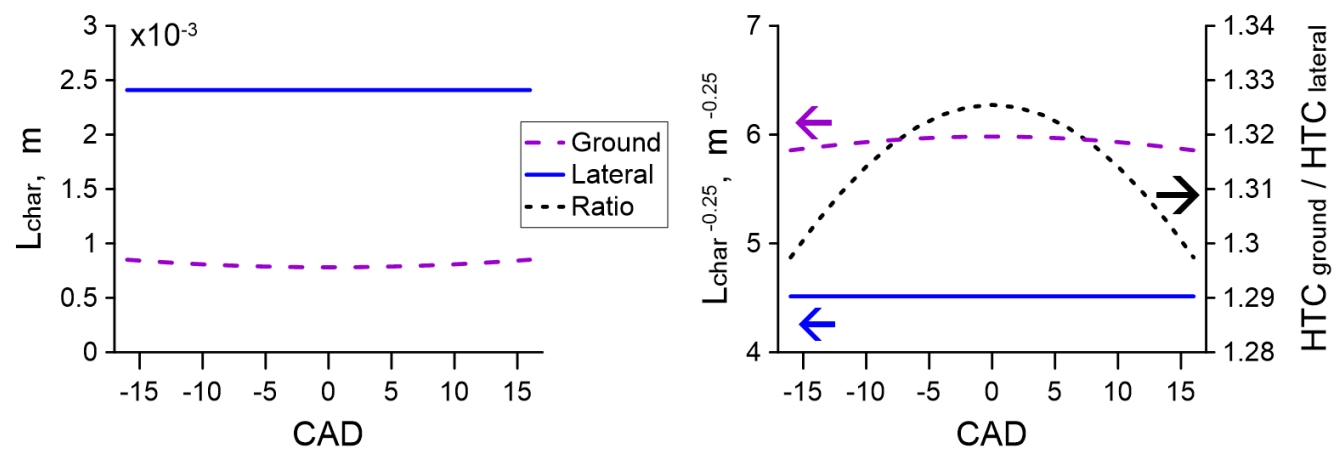

Figure 7: Sensitivity of HTC to characteristic length

Morels approach was considered suitable for this application. It takes into account the influence of velocity on convective heat in detail. In addition, it was conceived to provide an adequate spatial resolution. However, the presented procedure does not exclude the adoption of other heat flux correlations. The essential steps of the method would be maintained although the new correlation could require additional steps.

For instance, it is known that a phase lag between heat flux and bulk gas temperature takes place in closed reciprocating machines [46]. It can be modeled with an unsteady term which is proportional to the time-derivative of temperature [47]. This term is added to the conventional quasi-steady formulation of heat flux which is proportional to the temperature difference between gas and wall. Lawton [48] proposed an expression of the unsteady term proportional to the time-derivative of volume instead. 
His correlation was able to model the phase shift at different engine speeds under motoring conditions. Catto and Prata [49] did a numerical study of heat transfer in a gas spring. They found that both the correlations of Lawton and Kornhauser and Smith reproduced the simulation results for various fluids and operating conditions. More recently, Mathie et al. [50] developed a model for gas springs that considered both the conjugate and unsteady aspects of heat transfer. However, there is no agreement on how to model the unsteady aspect of heat transfer. Chang et al. [41] were able to fit a modified Woschni correlation to experimental measurements, without using an unsteady term. Consequently, the quasi-steady approach proposed by Morel was finally employed.

\section{Results and discussion}

\subsection{Influence of the injection strategy on gas motion}

In this section, the obtained velocity components are examined. It was possible to analyze the temporal evolution of velocity, the variations among the four zones defined at section 3.2, the differences among the injection strategy and the relative importance of each component in relation with the other ones.

First component to be examined was the velocity on the PIV plane obtained with the procedure described in section 3.2. The instantaneous evolution of this velocity is shown in figure 8 , where each plot depicts a zone and each profile a strategy. The highest peaks corresponded to the single injection strategy and they stood out from the other. This was observed in all zones. Zones 3 and 4 received earlier the influence of the injections, since the spray impinged on the lateral wall of the bowl. Zones 1 and 2 presented the highest peaks later, when the spray and the dragged gas moved over the bowl surface towards the piston axis. In the case of the single injection it could be observed that the gas slowed down from zones 3 and 4 to 1 and 2 . In zone 1 , a small peak appeared between 15 and 10 degrees before TDC but the highest velocities were found short after the TDC. Then, this velocity decreased. In zone 2 , in contrast, tangential velocity increased at the final stages of the measured span. In zone 3 , after the initial peaks, velocity evolved similarly to zone 2 . In zone 4 , lower velocity values were reached at the end.

Swirl velocities were obtained with the model described in section 2.2. Swirl evolution in the test with a single injection can be seen in figure 9 . In the figure, the curves with and without mechanical deformations and blow-by were plotted to assess the influence of those phenomena on gas motion. Effect of blow-by and mechanical deformations turned out to be significant, hence the velocity curves taking into account those processes were ultimately used. Blow-by and mechanical deformations weakened squish and therefore swirl in the piston bowl decreased. The effect was remarkable close to the TDC, when gas pressure was high. Swirl velocities in the double and triple injection tests were very similar to that of the single injection test.

Once turbulent kinetic energy was obtained using the method explained in section 3.3 , turbulent velocity was calculated with equation 14 for the only purpose of analyzing a variable which is comparable with the other velocity components. Turbulent velocity is shown in figure 10. The single injection strategy displayed the highest TKE in all zones, while the double injection strategy presented the lowest TKE. In zones 1 and 2, TKE increased towards the TDC and then decreased. In zones 3 and 4, there were peaks after the first injection. Around TDC, trends depended on the number 


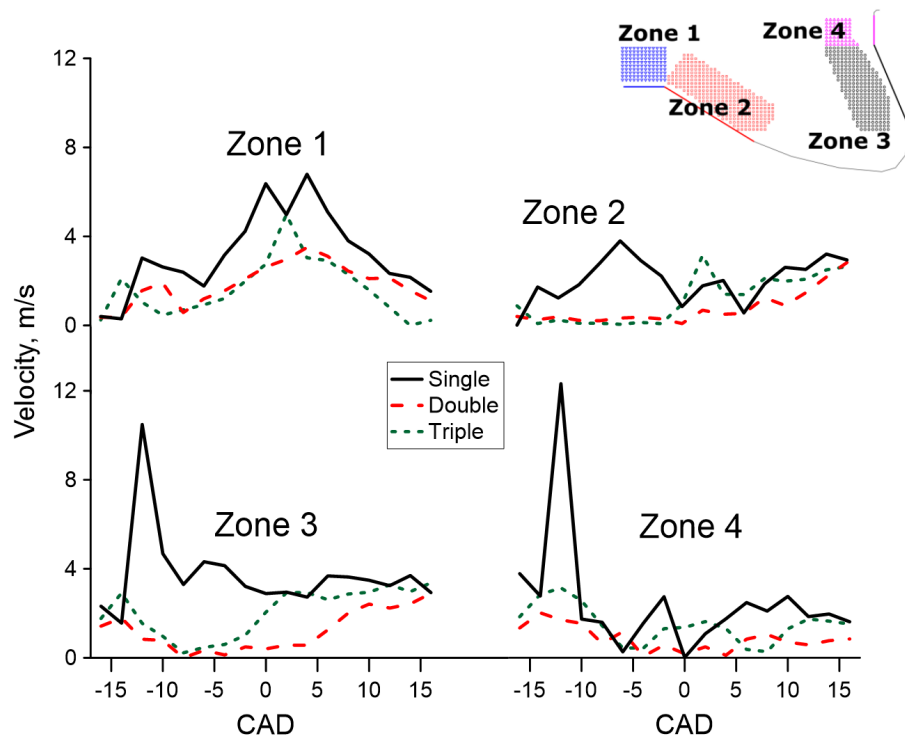

Figure 8: Gas velocity on the PIV plane tangential to piston surfaces

of injections but afterwards turbulence dissipated in all cases. Regarding the single injection case, the highest and earliest peak was found at zone 4 while the lowest and latest peak was found at zone 1 .

$$
v_{\text {turb }}(\theta)=\sqrt{2 T K E(\theta)}
$$

Comparing the order of magnitude of the previous velocity components, is possible to assert that all of them were similar and thus all components were significant to the final characteristic velocity determined with equation 11. This characteristic velocity can be seen in figure 11. Its value ranged between 5 and $20 \mathrm{~m} / \mathrm{s}$ in the single injection case and from 5 to $10 \mathrm{~m} / \mathrm{s}$ in the double and triple injection cases. In zones 1 and 2, velocity increased until TDC and afterwards started to decline. The triple injection

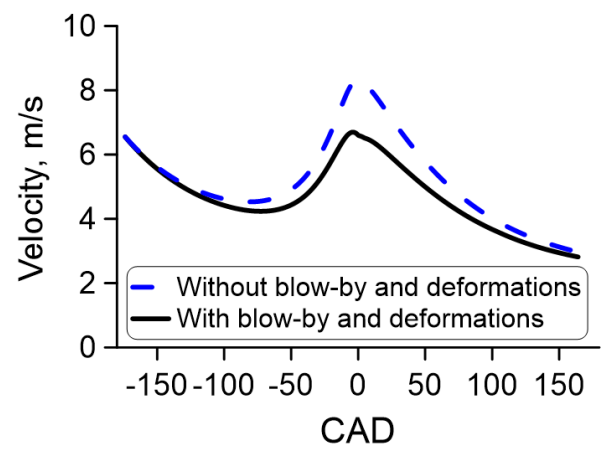

Figure 9: Swirl motion for the single injection case 


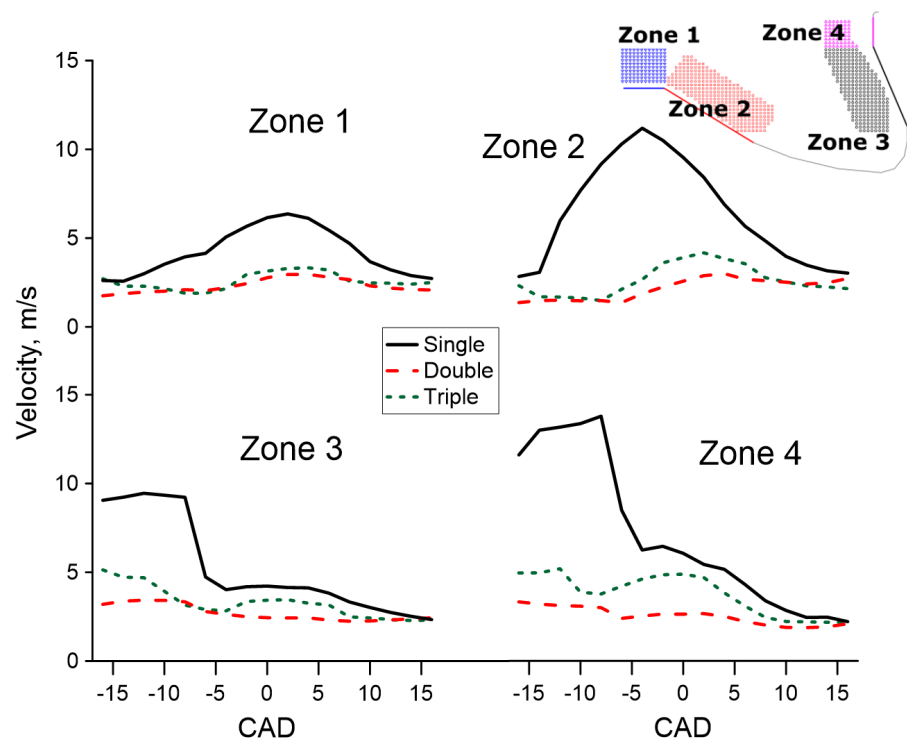

Figure 10: Turbulent velocity

strategy exhibited a peak close to the TDC in all zones. The trends of the other injection strategies depended on the zone. 


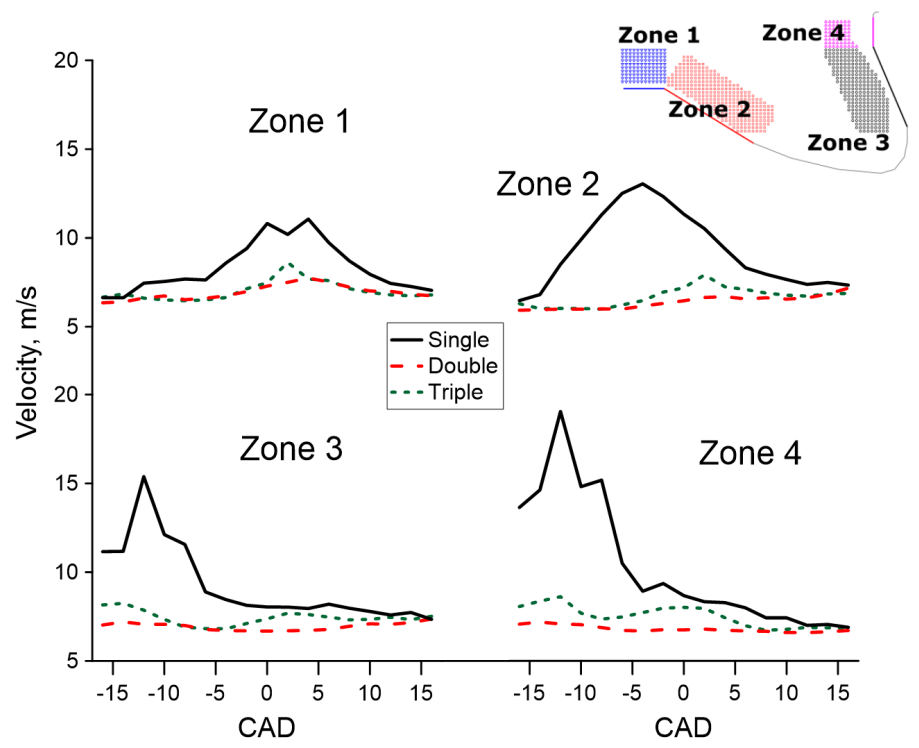

Figure 11: Characteristic velocity in the different zones

\subsection{Influence of the injection strategy on heat transfer}

This section presents and discusses the heat flux results. According to equation 9 heat flux depends on the heat transfer coefficient and on the temperature difference between the fluid and the surface. Since temperature of the solid was assumed constant, the evolution of heat transfer followed the trends of gas temperature and of the heat transfer coefficient. These variables were used to explain the observed trends of heat flux.

The heat transfer coefficient depends on the characteristic velocity, the characteristic length and the gas properties. Plots of HTC are found in figure 12. In comparison with the characteristic velocity seen in figure 11, HTC presented high values around TDC that were due to the fact that compression caused gas density to be high at that moment. In addition, zones 1 and 2 had higher HTC than zones 3 and 4 because of the lower characteristic length, as deduced from the analysis of figure 7 .

In figure 13, the evolution of heat flux density is displayed in the different zones and for the different injection strategies. In all cases, the peak of heat flux was located between 0 and 5 degrees after TDC. The triple injection curve started rising earliest while the single injection curve had the highest delay. Later, the single injection strategy reached the highest value of heat flux density after a steep increase. This was observed in all zones.

Gas temperature and rate of heat release are shown in figure 14. Comparing with figure 13, it can be seen that gas temperature had an essential influence on the shape of the heat flux curve. Gas temperature evolution was determined by the heat release rate, which was different for each injection strategy. Differences in the shape of the heat release rate are related to stratification. With a more distributed injection in the case of triple injection, there would be larger areas with low fuel-air ratio and low propensity to autoignite. Thus, heat release was more gradual. The single injection 


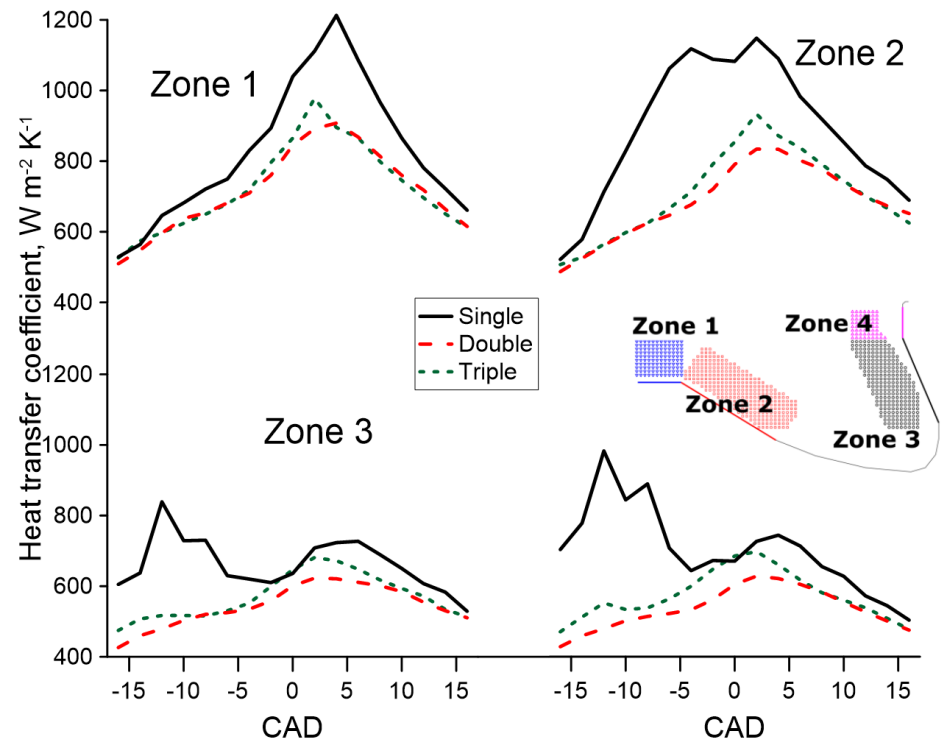

Figure 12: Heat transfer coefficient in the different zones

strategy, on the contrary, would present larger areas with fuel-air ratio close to 1. That explained the steeper slope in this case. These trends explain why each injection strategy rose earlier or later. It is interesting to note that even though the HTC had high values in some zones between angles 15 and 5 before TDC (see figure 12), heat flux was low because temperature difference was small. Therefore, to reduce heat transfer, lowering the temperature difference is as valid as reducing the HTC.

In figure 15 , data of figure 13 is reduced and only the mean and peak values of heat flux density are summarized. The analyzed interval was from -16 to $16 \mathrm{cad}$. Zones 1 and 2 presented similar values of mean heat flux density and they were clearly higher than those of zones 3 and 4 (between $20 \%$ and 30\%), which in turn were close to each other. Regarding peak heat flux density, there was also a difference between zones 1 and 2 on one hand and zones 3 and 4 on the other hand (between $25 \%$ and $40 \%$ ) but in this case the highest peak corresponded always to zone 1. This differences among zones can only be explained by variations of the heat transfer coefficient (see figure 12) because gas and wall temperatures were the same for all surfaces. Higher HTC of zones 1 and 2 induced higher values of mean heat flux density. The highest peak took place in zone 1 because it had the highest HTC when gas temperature was also high.

To finish, heat flux was assessed globally, without discerning among surfaces. This allowed to compare directly the different injection strategies and validate the trends already observed. To do that, a global heat flux density was calculated for each injection strategy as shown in equation 15, where $z$ is the corresponding zone.

$$
\dot{q}_{\text {global }}(\theta)=\frac{\sum_{z=1}^{4} \dot{q}_{z}(\theta) A_{z}}{\sum A_{z}}
$$

Figure 16 displays the evolution and the mean values of the global heat flux den- 


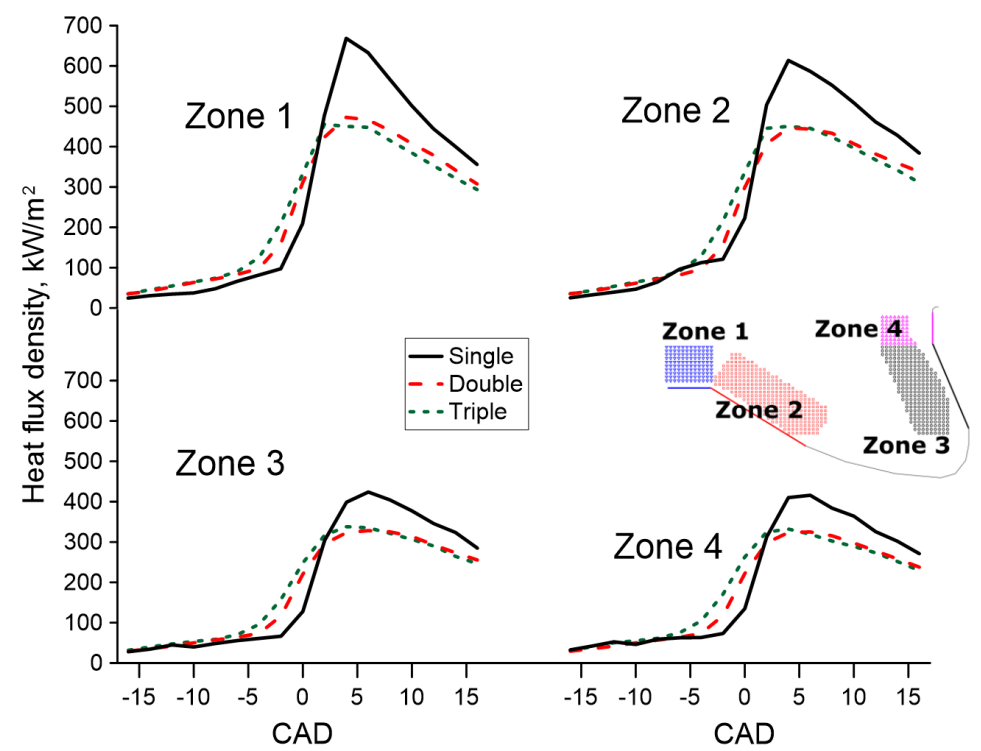

Figure 13: Heat flux density in the different zones

sity. The averaging interval was from -16 to $16 \mathrm{cad}$. It is confirmed that the injection strategy with the highest heat rejection was the single injection. This strategy presented the highest values of HTC and gas temperature, as can be seen in figures 12 and 14. Mean heat flux density was $7 \%$ higher for the single injection than for the case with three injections. An interesting finding is that heat flux was $4 \%$ higher with the triple injection strategy than with the double injection in spite of the latter having a higher peak of gas temperature. This can be explained because the HTC of the triple injection strategy was higher close to TDC when gas temperatures of both tests were similar. HTC was higher because gas velocity was higher. In conclusion, both gas velocity and temperature were crucial to interpret the heat transfer outcomes.
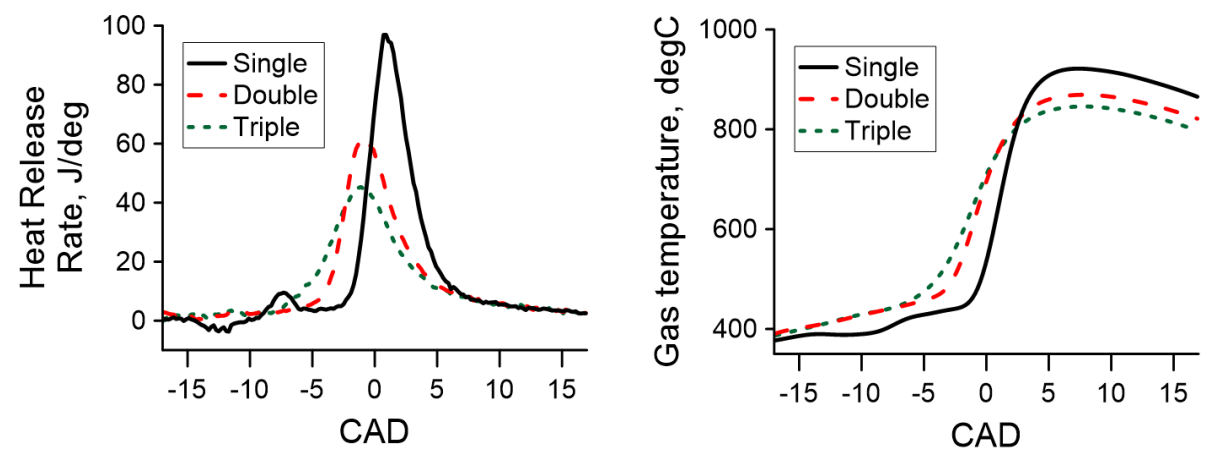

Figure 14: Gas temperature and heat release rate 

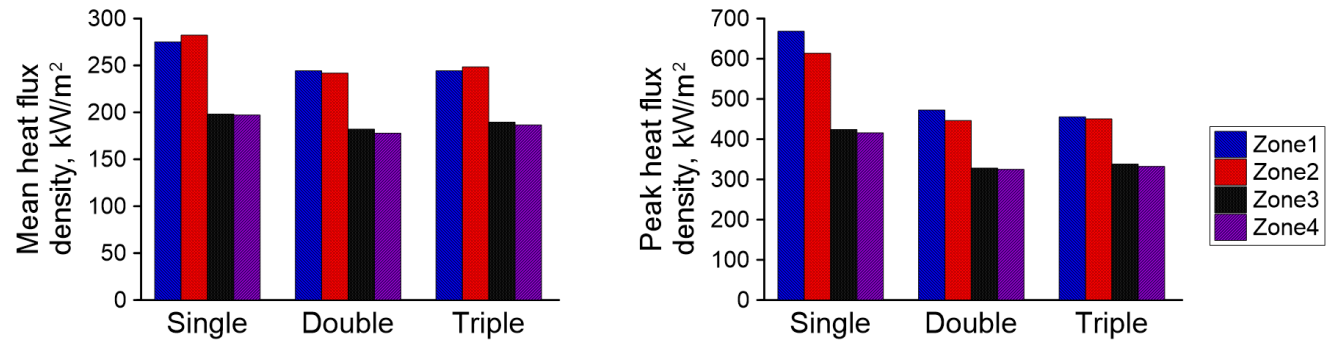

Figure 15: Mean and peak heat flux density in the different zones
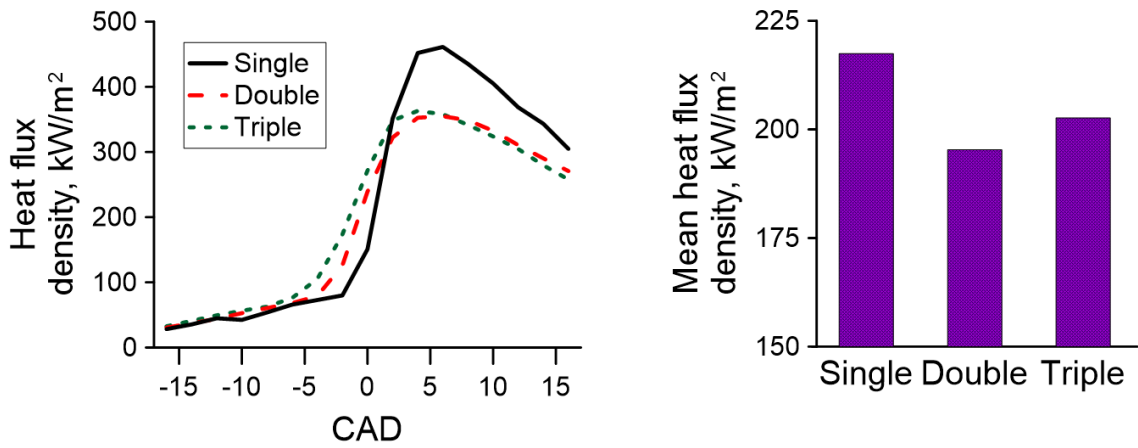

Figure 16: Heat flux density for different injection strategies

\section{Conclusions}

A method to calculate heat transfer was applied to study the influence of the number of injections on heat rejection to the piston bowl. The method was comprehensively explained and the models used as support tools were described. The procedure to refine the experimental measurements to obtain relevant magnitudes was also explained. Later, the influence of the injection strategy on gas motion and the HTC was analyzed in order to explain the heat transfer results. Regarding the method, the following conclusions were reached:

- A method for calculating heat transfer was developed using combined data obtained from experimental PIV measurements and computational models. The method is innovative in applying velocimetry data obtained in an optical engine to the calculation of heat transfer. The approach proposed by Morel was chosen because of its detailed attention to gas motion.

- All computed components of gas motion contributed significantly to the characteristic velocity.

- Trends of HTC were determined by gas velocity, density and boundary layer thickness.

The described approach allowed to compare heat flux density with different number of injections in various locations of the piston bowl and globally. Conclusions from this comparison are the following:

- Global results revealed that the injection strategy that presented the highest 
heat rejection was the single injection. Both gas velocity and temperature were the highest among all strategies.

- Heat flux with triple injection was $4 \%$ higher than with double injection. This was explained by higher flow velocities when gas temperature was similar around TDC. Heat flux with single injection was $7 \%$ higher than with triple injection.

- Central areas of the piston bowl received up to $40 \%$ more heat than lateral walls. This outcome was due to higher values of the HTC during the instants when gas temperature was high.

\section{Acknowledgments}

The authors gratefully acknowledge the Swedish Energy Agency and the Competence Center for Combustion Processes KCFP. The authors also would like to acknowledge that part of the work has been partially funded by the Spanish government under the grant "José Castillejo" (JC2015/0036). Research leading to this work has also received funding from Universitat Poli- tècnica de València through the contract FPI-S2-20161357 of "Programa de Apoyo para la Investigación y Desarrollo (PAID-01-16)".

\section{References}

\section{References}

[1] C. Silva, M. Ross, T. Farias, Analysis and simulation of low-cost strategies to reduce fuel consumption and emissions in conventional gasoline lightduty vehicles, Energy Conversion and Management 50 (2) (2009) 215 - 222. doi:10.1016/j.enconman.2008.09.046.

[2] B. Peng, H. Du, S. Ma, Y. Fan, D. C. Broadstock, Urban passenger transport energy saving and emission reduction potential: A case study for Tianjin, China, Energy Conversion and Management 102 (2015) 4 - 16, clean, Efficient, Affordable and Reliable Energy for a Sustainable Future. doi:10.1016/j.enconman.2015.01.017.

[3] S. Imtenan, M. Varman, H. Masjuki, M. Kalam, H. Sajjad, M. Arbab, I. R. Fattah, Impact of low temperature combustion attaining strategies on diesel engine emissions for diesel and biodiesels: A review, Energy Conversion and Management 80 (2014) 329 - 356. doi:10.1016/j.enconman.2014.01.020.

[4] A. García, J. Monsalve-Serrano, V. R. Roso, M. E. S. Martins, Evaluating the emissions and performance of two dual-mode RCCI combustion strategies under the World Harmonized Vehicle Cycle (WHVC), Energy Conversion and Management 149 (2017) 263 - 274. doi:10.1016/j.enconman.2017.07.034.

[5] V. Manente, B. Johansson, W. Cannella, Gasoline partially premixed combustion, the future of internal combustion engines?, International Journal of Engine Research 12 (3) (2011) 194-208. doi:10.1177/1468087411402441.

[6] V. Manente, P. Tunestal, M. Sonder, B. Johansson, Gasoline partially premixed combustion: high efficiency, low NOx and low soot by using an advanced combustion strategy and a compression ignition engine, International Journal of Vehicle Design 59 (108). doi:10.1504/IJVD.2012.048689. 
[7] Y. Takeda, N. Keiichi, N. Keiichi, Emission characteristics of premixed lean diesel combustion with extremely early staged fuel injection, in: International Fuels \& Lubricants Meeting \& Exposition, SAE International, 1996. doi:10.4271/961163.

[8] G. T. Kalghatgi, P. Risberg, H.-E. Angström, Advantages of Fuels with High Resistance to Auto-ignition in Late-injection, Low-temperature, Compression Ignition Combustion, in: Powertrain \& Fluid Systems Conference and Exhibition, SAE International, 2006. doi:10.4271/2006-01-3385.

[9] V. Manente, B. Johansson, P. Tunestal, W. Cannella, Effects of different type of gasoline fuels on heavy duty partially premixed combustion, SAE Int. J. Engines 2 (2009) 71-88. doi:10.4271/2009-01-2668.

[10] M. Shen, M. Tuner, B. Johansson, W. Cannella, Effects of EGR and Intake Pressure on PPC of Conventional Diesel, Gasoline and Ethanol in a Heavy Duty Diesel Engine, in: SAE Technical Paper, SAE International, 2013. doi:10.4271/2013-012702 .

[11] M. Kaiadi, B. Johansson, M. Lundgren, J. Gaynor, Experimental investigation on different injection strategies for ethanol Partially Premixed Combustion, SAE Technical Papers 2. doi:10.4271/2013-01-0281.

[12] J. Benajes, J. Martn, R. Novella, K. Thein, Understanding the performance of the multiple injection gasoline partially premixed combustion concept implemented in a 2-Stroke high speed direct injection compression ignition engine, Applied Energy 161 (2016) 465 - 475. doi:http://dx.doi.org/10.1016/j.apenergy.2015.10.034.

[13] S. Tanov, R. Collin, B. Johansson, M. Tuner, Combustion Stratification with Partially Premixed Combustion, PPC, using NVO and Split Injection in a LD - Diesel Engine, SAE International Journal of Engines 7 (4) (2014) 1911-1919. doi:10.4271/2014-01-2677.

[14] M. Izadi Najafabadi, S. Tanov, H. Wang, B. Somers, B. Johansson, N. Dam, Effects of injection timing on fluid flow characteristics of partially premixed combustion based on high-speed particle image velocimetry, SAE International Journal of Engines 10 (4). doi:10.4271/2017-01-0744.

[15] G. Kalghatgi, L. Hildingsson, B. Johansson, Low NOx and Low Smoke Operation of a Diesel Engine Using Gasolinelike Fuels, Journal of Engineering for Gas Turbines and Power 132 (9) (2010) 092803-9. doi:10.1115/1.4000602.

[16] G. Borman, K. Nishiwaki, Internal-combustion engine heat transfer, Progress in Energy and Combustion Science 13 (1) (1987) 1 - 46. doi:10.1016/03601285(87)90005-0.

[17] K.-W. Cho, D. Assanis, Z. Filipi, G. Szekely, P. Najt, R. Rask, Experimental investigation of combustion and heat transfer in a direct-injection spark ignition engine via instantaneous combustion chamber surface temperature measurements, Proceedings of the Institution of Mechanical Engineers, Part D: Journal of Automobile Engineering 222 (11) (2008) 2219-2233. doi:10.1243/09544070JAUTO853.

[18] H. Fridriksson, B. Sunden, S. Hajireza, M. Tuner, CFD Investigation of Heat Transfer in a Diesel Engine with Diesel and PPC Combustion Modes, in: SAE International Powertrains, Fuels and Lubricants Meeting, SAE International, 2011. doi:10.4271/2011-01-1838.

[19] T. Morel, P. N. Blumberg, E. F. Fort, R. Keribar, Methods for heat transfer and temperature field analysis of the insulated diesel, Phase I, DOE/NASA/0342-1 NASA CR-174783. 
[20] J. Benajes, P. Olmeda, J. Martín, D. Blanco-Cavero, A. Warey, Evaluation of swirl effect on the Global Energy Balance of a HSDI Diesel engine, Energy 122 (2017) 168 - 181. doi:10.1016/j.energy.2017.01.082.

[21] W. Colban, I. Ekoto, D. Kim, P. Miles, In-cylinder PIV measurements in an optical light-duty diesel at LTC conditions, Proceedings of the THIESEL 2008.

[22] H. Zhao, N. Ladommatos, Optical diagnostics for in-cylinder mixture formation measurements in IC engines, Progress in Energy and Combustion Science 24 (4) (1998) 297 - 336. doi:10.1016/S0360-1285(98)80026-9.

[23] C. Jin, Z. Zheng, A review on homogeneous charge compression ignition and low temperature combustion by optical diagnostics, Journal of Chemistry 2015 (910348). doi:10.1155/2015/910348.

[24] S. H. R. Müller, B. Böhm, M. Gleißner, R. Grzeszik, S. Arndt, A. Dreizler, Flow field measurements in an optically accessible, direct-injection spray-guided internal combustion engine using high-speed PIV, Experiments in Fluids 48 (2) (2010) 281-290. doi:10.1007/s00348-009-0742-2.

[25] S. Soid, Z. Zainal, Spray and combustion characterization for internal combustion engines using optical measuring techniques: A review, Energy 36 (2) (2011) 724 - 741. doi:10.1016/j.energy.2010.11.022.

[26] L. M. Pickett, D. L. Siebers, Non-Sooting, Low Flame Temperature MixingControlled DI Diesel Combustion, in: SAE 2004 World Congress \& Exhibition, SAE International, 2004. doi:10.4271/2004-01-1399.

[27] Z. Wang, S. Tanov, H. Wang, M. Richter, B. Johansson, M. Alden, HighSpeed Particle Image Velocimetry Measurement of Partially Premixed Combustion (PPC) in a Light Duty Engine for Different Injection Strategies, in: SAE Technical Paper, SAE International, 2015. doi:10.4271/2015-24-2454.

[28] R. P. Lucht, D. Dunn-Rankin, T. Walter, T. Dreier, S. C. Bopp, Heat transfer in engines: Comparison of cars thermal boundary layer measurements and heat flux measurements, in: International Congress \& Exposition, SAE International, 1991. doi: $10.4271 / 910722$.

[29] R. R. Steeper, E. J. Stevens, Characterization of Combustion, Piston Temperatures, Fuel Sprays, and Fuel-Air Mixing in a DISI Optical Engine, in: SAE Technical Paper, SAE International, 2000. doi:10.4271/2000-01-2900.

[30] P. C. Ma, T. Ewan, C. Jainski, L. Lu, A. Dreizler, V. Sick, M. Ihme, Development and Analysis of Wall Models for Internal Combustion Engine Simulations Using High-speed Micro-PIV Measurements, Flow, Turbulence and Combustion 98 (1) (2017) 283-309. doi:10.1007/s10494-016-9734-5.

[31] J. M. Garcia-Oliver, A. Garcia, A. Gil, L. Pachano, Study of Air Flow Interaction with Pilot Injections in a Diesel Engine by Means of PIV Measurements, SAE International Journal of Engines 10 (3). doi:10.4271/2017-01-0617.

[32] S. Tanov, Z. Wang, H. Wang, M. Richter, B. Johansson, Effects of Injection Strategies on Fluid Flow and Turbulence in Partially Premixed Combustion (PPC) in a Light Duty Engine, SAE Technical Paper 2015-24-2455. doi:10.4271/2015-24-2455.

[33] A. V. Bueno, J. A. Velásquez, L. F. Milanez, Internal Combustion Engine Indicating Measurements, Applied Measurement Systemsdoi:10.5772/37889. 
[34] M. Lapuerta, R. Ballesteros, J. R. Agudelo, Effect of the gas state equation on the thermodynamic diagnostic of diesel combustion, Applied Thermal Engineering 26 (2006) 1492-1499.

[35] M. Lapuerta, O. Armas, J. Hernández, Diagnosis of DI Diesel combustion from in-cylinder pressure signal by estimation of mean thermodynamic properties of the gas, Applied Thermal Engineering 19 (5) (1999) 513-529. doi:http://dx.doi.org/10.1016/S1359-4311(98)00075-1.

[36] A. Murakami, M. Arai, H. Hiroyasu, Swirl measurements and modelling in direct injection diesel engines, SAE Technical Paper 880385. doi:10.4271/880385.

[37] F. Payri, P. Olmeda, J. Martín, A. García, A complete 0D thermodynamic predictive model for direct injection diesel engines, Applied Energy 88 (12) (2011) 4632-4641. doi:10.1016/j.apenergy.2011.06.005.

[38] A. J. Torregrosa, P. Olmeda, J. Martín, C. Romero, A Tool for Predicting the Thermal Performance of a Diesel Engine, Heat Transfer Engineering 32 (10) (2011) 891-904. doi:10.1080/01457632.2011.548639.

[39] A. Broatch, P. Olmeda, A. García, J. Salvador-Iborra, A. Warey, Impact of swirl on in-cylinder heat transfer in a light-duty diesel engine, Energy 119 (2017) 10101023. doi:10.1016/j.energy.2016.11.040.

[40] C. D. Rakopoulos, G. C. Mavropoulos, D. T. Hountalas, Measurements and analysis of load and speed effects on the instantaneous wall heat fluxes in a direct injection air-cooled diesel engine, International Journal of Energy Research 24 (7) (2000) 587-604. doi:10.1002/1099-114X(20000610)24:7¡587::AIDER604¿3.0.CO;2-F.

[41] J. Chang, O. Gralp, Z. Filipi, D. N. Assanis, T.-W. Kuo, P. Najt, R. Rask, New Heat Transfer Correlation for an HCCI Engine Derived from Measurements of Instantaneous Surface Heat Flux, in: SAE Technical Paper, SAE International, 2004. doi:10.4271/2004-01-2996.

[42] J. Desantes, A. Torregrosa, A. Broatch, P. Olmeda, Experiments on the influence of intake conditions on local instantaneous heat flux in reciprocating internal combustion engines, Energy 36 (1) (2011) 60 - 69. doi:10.1016/j.energy.2010.11.011.

[43] G. Davis, C. Borgnakke, The Effect of In-Cylinder Flow Processes (Swirl, Squish and Turbulence Intensity) on Engine Efficiency Model Predictions, SAE Technical Paper 820045. doi:10.4271/820045.

[44] R. C. Zeller, R. O. Pohl, Thermal conductivity and specific heat of noncrystalline solids, Phys. Rev. B 4 (1971) 2029-2041. doi:10.1103/PhysRevB.4.2029.

[45] R. Brodkey, H. Hershey, Transport Phenomena: A Unified Approach, Brodkey Publishing, 2003.

[46] K. Lee, A simplistic model of cyclic heat transfer phenomena in closed spaces, Vol. 2, Intersoc. Energy Convers. Eng. Conf., 1983.

[47] A. Kornhauser, J. Smith, Application of a complex Nusselt number to heattransfer during compression and expansion, Journal of heat transfer - Transactions of the ASME 116 (3) (1994) 536-542. doi:10.1115/1.2910904.

[48] B. Lawton, Effect of compression and expansion on instantaneous heat transfer in reciprocating internal combustion engines, Proceedings of the Institution of Mechanical Engineers, Part A: Journal of Power and Energy 201 (3) (1987) 175186. doi:10.1243/PIME_PROC_1987_201_022_02. 
[49] A. Catto, A. Prata, A numerical study of instantaneous heat transfer during compression and expansion in piston-cylinder geometry, Numerical Heat Transfer; Part A: Applications 38 (3) (2000) 281-303. doi:10.1080/10407780050136530.

[50] R. Mathie, C. Markides, A. White, A framework for the analysis of thermal losses in reciprocating compressors and expanders, Heat Transfer Engineering 35 (16-17) (2014) 1435-1449. doi:10.1080/01457632.2014.889460. 